\title{
Principals, Information Technology and leadership: coping with professional development despite isolation
}

\author{
William Newman \\ P. O. Box 1420 \\ Alice Springs, Northern Territory \\ Australia \\ Tele + 618 89525044; Fax + 61889527210 \\ E-mail:wnewman@pobox.com
}

\begin{abstract}
Shaping the use and direction of Information Technology in a school is not an easy task. Since principals are the decision makers and driving force in educational institutions they must play a pivotal role but many lack the IT skills and knowledge to do so. The Australian Principals Association Professional Development Council project targets the changing of attitudes and work habits among principals via a self-paced learning program using the Internet. It is designed to provide a structure of security for all levels of ability and is a systemwide approach to professional development.
\end{abstract}

\section{Keywords}

Attitudes, distance learning, electronic mail, Internet, national projects, professional development

\section{INTRODUCTION}

How far have the developed countries advanced in terms of system-wide utilisation of Information Technology (IT) in education? I would suggest not very far at all. It is important to distinguish between what happens in individual schools and what is the norm. Some schools will excel in IT implementation but are a minority. They succeed as a result of individual vision and energy, and not as a result of 
system wide sustainable initiatives. The sad reality of most Western education systems is that Information Technology is not integrated across the school curriculum in a pedagogically sound manner. There is no doubt that computers exist in schools and that they are being used, but how they are being used is often not addressed.

Even as we approach the next millennium too many schools are focused on the hardware and its costs without placing technology in the bigger picture. Costs cannot be ignored, but they must be considered in relation to the gains they provide and the human structures that must go with IT implementation.

Why, despite all the rhetoric, have systems not progressed in their use of the technology? It would be foolish to suggest that any one factor is responsible but from experiences in the Northern Territory of Australia one significant factor has been identified - the principal.

\section{Why Target Principals?}

Principals are the decision makers and driving forces in educational institutions. If they do not have an insight into the use of the technology, then its meaningful implementation will be limited. Traditional thinking is important but not necessarily what is required to implement IT in a pedagogically sound way into the learning process. It is easy for principals to simply do what has been done before and follow others in conservatism. The conventional wisdom within primary schools is to place computers at the disposal of students without ensuring that educators have the appropriate skills to use IT as a tool. Despite modeling being a recognised teaching/learning approach little exists within a classroom in terms of the use of Information Technology. Principals must be prepared to support staff in gaining skills and modeling behaviour.

In Australia the trend is for all education authorities to move to a self-managed or devolved management and financial model. This places considerable power and responsibility with the principal in terms of setting, supporting and maintaining any program involving the use of IT. The principal is the lynch pin.

Without adequate professional development principals will not have the IT knowledge, skills and, most importantly, the insight to initiate and support IT implementation in schools. Principals must provide support for real educational benefits and not be solely reliant on the views and advice of others. They must have a level of understanding that will enable them to make decisions based on information presented to them. Fundamental to this is an understanding of what IT in the school is for and what its role should be.

One of the common catch cries often heard in the school sector in Australia is 'Industry uses these types of computers therefore so should our school'. This can be a very powerful argument to the noneducationalists and one that has been very common over the years. Arthur Tatnall and Paul Jenner (1986) encapsulated the attitudes when they said:

'... many people do not understand how and why computers are used in education, making the mistake that either they are used in the same way as in business or else just for drill and practice activities. This presents a problem that needs constant addressing'. 
Keeping in mind that this was written in 1986 it is sad to think that it still rings true today. Not only that, it is an attitude that exists within education itself and the connection to business is one that can easily be used on IT-illiterate principals. Principals, above all others, must be aware of this attitude, and be able to combat it based on their own experience and knowledge. To do this requires a skill level and understanding that the majority of them do not have.

It is vitally important that developing countries focus on the human structure for the use of IT as much as they concentrate on the acquisition of the technology itself. IT in education is about people, not simply hardware. The hardware alone will never be able to provide improved learning outcomes for any education system. What is needed are educators and leaders with the insight to use IT as a tool within the school. Principals who can sort the hype from the reality and address issues in a proactive rather than reactive manner will be more than just managers, they will be leaders. To do this requires a human infrastructure of support and guidance.

\section{Support for principals}

The Australian Principals Associations Professional Development Council (APAPDC http//:www.edprog.tased.edu.au/apapdc/home.html) is a national body that represents all Australian principals regardless of the type and size of the school, and facilitates professional development among principals.

According to the APAPDC, 'In 1983, Professor Judith Chapman undertook significant research into the profile of Australia's school principals, on behalf of the Australian Schools Commission. No further research has been undertaken on the subject until the APAPDC commissioned a team led by Dr Neville Grady from the University of Tasmania at Launceston to undertake follow-up research'. This highlights that research on principalships has been few and far between.

From the work that has been done, Evans (1996) said principals must have the following competencies: Educational leadership, organisational management, organisational leadership, political leadership and reflective leadership. The competencies were created as a part of a strategy to identify the key areas in which principals must have skills and knowledge in order to prove successful as a principal.

The common thread through all of the profiles were the words 'interpret', 'vision' and 'communication' - interpret, vision and communicate in a world that can only be described as alien in comparison to most principals' own schooling experience. Where do they acquire the basic skill set in modern technology that will enable them to survive? It is of limited value to simply provide a resource as rich as the Internet to principals and assume that they then have all the answers. A number of informal trials facilitated by Roy Harvey of the Northern Territory Principals Association have taken place where principals were provided the tools and the location of 'useful information', but never obtained the information. Giving principals the tools without the skills, and without developing their confidence in the use of the tools and their own ability will not yield any positive outcomes. It cannot be assumed that just because children have a pencil and paper they will write meaningful passages of work.

One of the greatest difficulties facing the APAPDC is effectively reaching all principals. For this reason a project was established in the Northern Territory to 
find a model that could deliver professional development in an efficient and cost effective manner.

The Northern Territory covers a geographical area 5.5 times the size of the United Kingdom and 3.5 times the size of Zimbabwe. Despite its size it has a population of only 195101 of which 112845 are in the two largest centres separated by 1500 kilometres. The remaining 82256 people are scattered throughout the Territory in small communities. Such communities often have small schools and are accessible only by four wheel drive vehicles. Some schools are up to 12 hours travel from their nearest support centre. Providing professional development in this context is extremely difficult.

The Internet was seen as a medium to deliver professional development, not only to principals in remote locations, but also those in urban centres. Many professional development programs exist on the Internet that cover a range of issues from Leadership to Behaviour Management but they all assume that the principal already has the skills to use the medium. The reality is somewhat different.

In order to tap into Internet resources principals need to have a basic skill set that was simply not there. The APAPDC project targets skill development via a selfpaced learning model independent of geographical location. It is designed to provide a structure of security for all levels of ability. The results of the program thus far have been very impressive. Those completing the course have the skills to now use the wealth of resources that exist in the global community via the Internet.

Darling-Hammond and McLaughlin (1995) write that, according to Cohen, McLaughlin and Talbert (1993) the outlines of a new paradigm for professional development policy are emerging and the hard work of developing concrete exemplars of the policies and practices that model 'top-down support for bottom-up reform' has only just begun. The APAPDC project provides just such an approach.

The APAPDC project provides a course where principals get an individual professional development program that is completed in their own time at their own location. It is individual in the sense that they work at their own pace, and have a person who monitors their progress and provides tasks and feedback to those tasks.

The aims of the course are to:

- $\quad$ provide a professional development opportunity to principals who would not have otherwise had, or created for themselves, the opportunity;

- develop a model that would resist the itinerant nature of staffing in remote areas, and provide an ongoing mechanism for principals to acquire and further develop skills in the use of the Internet and information technology generally;

- ensure the skill set of principals was such that they could utilise the Internet as a medium for professional development on a range of topics not related to IT;

- enlighten principals about the educational value and issues associated with IT in a school environment. 
The program was introduced during the 1996 calendar year. It was initially in two parts with principals being given the option to stop at the completion of part one. No one took this option.

The basic mode of delivery was to supply all participants with a booklet containing general information on the Internet and introducing them to the jargon. It also contained the first five tasks. The tasks involved the principal reading the information on how to do something associated with the Internet and then completing an activity.

Grady and Mulford (1996) point out that, 'There seems to be an understanding underlying the more highly-developed programs that success comes from following a developmental process, e.g., one program is sequenced on the basis of what a principal needs for survival, then for control, then for stability, and then for taking initiatives'. The program is designed to achieve exactly that.

The program makes use of a mentor to work with the principal as a fundamental part of the course. The mentor in the early stages of the course was the original author of the course. Once the first group of principals had completed the course they then made themselves available as mentors for other principals. This has a two-prong advantage. Principals becoming mentors cements their own knowledge in the area and the project provides for a sustainable model -principals mentoring principals.

The complete course consists of three parts. Part one covers electronic mail, part two covers the World Wide Web (WWW) and part three puts the first two topics into a context by providing professional development on leadership. The focus for part three is not the technology and skill acquisition, but the content and issues of leadership.

Part one consists of 25 tasks and concentrates on e-mail using Eudora. Eudora was chosen for reasons outlined further on. The idea behind doing e-mail first was to ensure that principals had a set of basic skills that they could call on later in the program. It highlights the fact that the very nature of communication is changing. In addition, once e-mail is mastered all future problems for any professional development can be dealt with via e-mail.

Even though some principals had used e-mail they were generally unaware of the power and sophistication of a mail program such as Eudora. Part one presented a challenge for IT-illiterate principals as well as those who had used e-mail before.

Part two looks at using the World Wide Web and Netscape. There are only 16 tasks but they take longer to complete and are more conceptually challenging. People enjoyed and relished the challenge of this section.

Part three takes the skills associated with searching the WWW and using e-mail, and leads the principal through a course on issues associated with leadership in schools. This part is not concerned solely with IT in schools but a range of issues facing principals in the leadership of their school.

With all three parts participants cannot move onto the next task until their mentors have sent it to them. This has worked very well and provides for the following:

- It ensures a consistent use of the technology by principals.

- It allows the mentors to be convinced that the principals do understand the concepts and skills associated with the task they have just completed. 
- It allows the mentors to monitor and, if necessary, contact the principals over their progress.

\subsection{Tasks}

For parts one and two of the program the tasks contain information and instructions on discrete skills. At the end of each of the tasks is an activity that principals complete and send to their mentors.

The tasks are written with two key factors in mind. First, each task has to cover a very small skill set. Second, each task has to be achievable in a relatively short period of time. Each task is written to take approximately half an hour to an hour to complete and constructed to be self-paced. Principals are very busy and need a structure where they can put something down for a month and come back to it without going over old ground.

The mentors ensure the principals have mastered the concepts and, once happy with the response, the mentors send, via e-mail, the next task to the principals. This means a principal cannot skim through the material but must master each small component on the road to completion.

\subsection{Mentoring}

Central to the model is the use of a mentor who provides feedback and monitors individual progress. If principals are not checking their mail the mentor will contact them and sort out any problems. The mentors are also responsible for sending out articles of professional interest to principals.

The success of the project stems largely from its use of mentors and their interaction with the participants. The use of mentors has been shown in a wide range of environments to be highly effective. This is highlighted by the work of Aubrey and Cohen (1995) who looked at where learning comes from and its relation to a principal. They found that in answer to the question, 'Where did you learn what is most useful to you in your working life?' the most often cited answers were a high pressure project, a major 'screwup', a career change or a nondogmatic mentor.

Other work by Grady and Mulford (1996) shows that 'the relatively widespread use of some form of mentoring system means that many inductees will retain a degree of control over the process'. The establishment of Professional Development Schools (PDS) in the USA further highlights the success of a mentor approach to learning.

The mentors spend considerable online time communicating with their principals on an individual basis to ensure they feel confident and secure in knowing help is there, and the mentor relationship is the fundamental cornerstone to the success of the project. It is important that the mentors respond to people quickly and in a meaningful way. The feedback associated with the use of a mentor has been exceptional. 


\subsection{Timing}

From those who have completed the project it appears that the time required to complete both parts one and two is approximately 20 weeks. Part three is currently being trialed.

One of the strengths of the program is that principals can work on tasks when it suits them. If things are really hectic they may not complete a task for a month and then might do three in one week.

\subsection{Resources}

The key elements to the program can be divided into the model itself, the hardware, the software, access to the Internet and the mentor. The three that have not been previously mentioned are software, hardware and access to the Internet.

The software chosen for the program had to fit two essential criteria:

- It was legal. It is vitally important that only software that can be legally used in schools without cost be used in the program.

- It would run on most machines. The variety and power of computers that were and are to be used for this program is extreme. The software needed to be such that it would run reliably on lower-end machines as well as high-powered RISC machines.

In addition to the above criteria Eudora and Netscape were chosen because they are multiplatform. The hardware was not selected but was already in place, in essence whatever was already out there and could be connected to the Internet was to be used.

Internet access is the only infrastructure component that cannot be directly controlled by the principal or mentor. Quality and cost of access will vary from country to county.

\section{BENEFITS TO PRINCIPALS}

The change in confidence and attitude has been one of the most striking consequences of the program. In Alice Springs, for example, all urban principals are doing or have completed the program. All members of the executive of the Northern Territory Principals Association (NTPA) have completed or are doing the program. As a direct result of being involved in the program the principals have all placed IT as a priority area for their own future professional development as well as making it a priority for their schools.

An increased amount of electronic communication is now taking place. All correspondence for the executive committee of the NTPA now takes place electronically. Mailings of reading and association business are sent out electronically with no hard copy mailings occurring beyond 1997. If principals do not have their own account and connection to the Internet they will miss all mailings and association information that is being circulated. The time and cost savings of this approach is considerable, and has been made possible as a direct consequence of principals completing the APAPDC program. 
On a local level principals now have computers on their desk with Internet access and are modeling IT use. The fact it is on their desks has prompted a shift of attitude, and principals are becoming more aware of the potential and the limitations of the technology. As a result of the program the majority of principals are now looking at how e-mail can be introduced at a school level to give electronic access to their staff.

The most significant outcome of the program is that principals are in a position to understand the potential and to ask the right questions when others present ideas or plans in terms of IT implementation at the school level. Confidence in not being seen as a Luddite has enabled principals to start down the track of genuine development.

\section{4}

\section{CONCLUSION}

Apart from the Internet infrastructure, concentrating on hardware and availability of computers alone will never succeed. Providing teacher training without having principals and decision-makers being conversant with the potential of the technology will be a slow and ultimately frustrating experience for teachers. For IT to be used as a tool in a pedagogically sound way requires an insight by teachers and decision-makers that can be best obtained by skill acquisition and, most importantly, modeling. If principals do not have skills and knowledge they are at the mercy of the techno-fix enthusiasts in the school, who are often keen on the technology for technology's sake. Even those who are keen to see the technology applied in a pedagogically sound manner often lack the skills and insight to ensure that it becomes a reality.

One step in the direction of sound, educationally valid uses of IT in schools is to ensure that the principal has the appropriate skills and insight. The cost of developing individual programs for all principals to achieve this is prohibitive. The model outlined here has shown itself to be a successful and economical way of providing professional development to all principals regardless of location and size of school.

It must be kept in mind that the project is more than just a professional development program on the Internet itself. It gives principals skills that can be used for a diverse range of noncomputing professional development and communication activities. It is providing a medium for the future delivery of a wide range of programs covering all aspects of leadership.

At the IFIP Fifth World Conference on Computers in Education no papers specifically covered the need for educational leaders to be conversant with issues relating to IT or the skilling of our leaders in this area. Without such skilling developing countries will follow the same slow and frustrating path followed by developed countries in terms of the pedagogical uses of IT within education. Grady and Mulford (1996) said 'management' is concerned largely with 'doing things right' and 'leadership' largely with 'doing the right things', and they thought that attention usually favours 'management' over 'leadership'. Until the balance is addressed principals will remain managers and not leaders of IT in education, and as such will struggle to develop and implement policy that will ultimately ensure improved learning outcomes of students. 
Darling-Hammond and McLaughlin (1995) point out that 'What does need to be a permanent addition to the policy landscape is an infrastructure or web of professional development opportunities that provides multiple and ongoing occasions for critical reflection, and that involves teachers with challenging content'. This applies equally as well to principals. They explain that capacity building policies view knowledge as constructed by and with practitioners for use in their own contexts rather than as something conveyed by policy-makers as a single solution for top-down implementation. If such capacity is to be built then principals and decision-makers must acquire the basic skill set they need in their own environment with nonthreatening support.

Developing countries should not simply follow the trends of the developed countries believing they have the answers. There are no answers, just experiences. It is important for developing countries to look beyond individual schools and look at system-wide initiatives. By comparing and contrasting the two they will be in a far better position than many of our educational systems are today.

REFERENCES

Aubrey, R. and Cohen P. (1995) Working Wisdom: Timeless Skills and Vanguard Strategies for Learning Organizations. Jossey-Bass, San Francisco, CA.

Cohen, K., McLaughlin, W. and Talbert, J. (1993) Teaching for Understanding: Challenges for Policy and Practice. Jossey-Bass, San Francisco, CA.

Darling-Hammond, L. and McLaughlin, W. (1995) Policies that support professional development in an era of reform, Phi Delta Kappan, 597.

Evans, D. (1996) Leaders and Their Learning, APAPDC Publications, Canberra, Australia.

Grady, N. and Mulford, B. (1996) National Principals Induction Survey, Report to the Australian Principals Associations Professional Development Council.

Tatnall, A. and Jenner, P. (1986) How state education authorities recommend computer systems for use in Australian schools, Computers in Education, CEGV eighth annual conference.

\section{6}

\section{BIOGRAPHY}

Bil Newman has a Masters Degree in Applied Science (Artificial Intelligence) to complement his original degree and other postgraduate studies in education and mainstream computing. He is the only recipient of the Computer Association's Northern Territory Computer Educator of the Year award and was in the first group of 11 teachers in Australia to receive Master Teacher 3 status. To this day he remains the youngest ever recipient.

Bil is currently the senior computing adviser for the Operations South Region of the Northern Territory of Australia. Previously he worked in senior computing at Centralian College, has lectured for the Northern Territory and Swinburn Universities, and operated a consultancy business. Bil is currently listed in several international biographical references including Who's Who of the World and the Who's Who in Science and Engineering. 